ఠ

\title{
Fixed-dose combination of sitagliptin and metformin for the treatment of type 2 diabetes
}

This article was published in the following Dove Press journal:

Diabetes, Metabolic Syndrome and Obesity:Targets and Therapy 30 July 2009

Number of times this article has been viewed

\section{Jonathan K Reynolds}

Washington State University, College of Pharmacy, Pullman, WA, USA
Correspondence: Jonathan K Reynolds Washington State University, College of Pharmacy, PO Box 646710, Pullman, WA 99164-6710, USA

Email jreynolds@wsu.edu
Abstract: Janumet ${ }^{\mathrm{TM}}$, a fixed dose combination of sitagliptin/metformin HCL manufactured by Merck Pharmaceuticals, has received US Food and Drug Administration approval for treatment of patients with type 2 diabetes, that are inadequately controlled, either by sitagliptin or metformin alone or together in free-dose combination form. Sitagliptin, an inhibitor of the enzyme DDP-4, assists patients with type 2 diabetes mellitus to achieve glycemic control. It has been shown to be safe and effective at $100 \mathrm{mg}$ daily doses. The effect of giving sitagliptin in combination with metformin is thought to have a complimentary and possibly additive effect on glycemic control.

Keywords: sitagliptin, metformin, fixed-dose combination, dipeptidyl peptidase-4 inhibitor, DPP-4 inhibitor

\section{Introduction}

In 2007 it was estimated that 17.9 million Americans were diagnosed with type 2 diabetes mellitus (T2DM). Additionally it was estimated that 5.7 million people had T2DM but were undiagnosed at the time. Together these numbers suggest that 23.6 million people or $7.8 \%$ of the population of the United States that have T2DM. In 2007 in the USA an estimated 1.6 million people were diagnosed with T2DM and that 57 million Americans over the age of 20 years have impaired fasting glucose or prediabetes. ${ }^{1}$

There is strong evidence demonstrating that benefits can be achieved from tight glycemic control. ${ }^{2-5}$ Many patients with T2DM remain uncontrolled despite a wide range of treatment options available to treat patients with T2DM including metformin, sulfonylureas, meglitinides, $\alpha$-glucosidase inhibitors, thiazolidinediones, and insulin. ${ }^{6}$ It was found that the average glycosylated hemoglobin (A1C) of patients with a diagnosis of DM increased from $7.7 \%$ to $7.9 \%$ between 1990 and $1999 .{ }^{2}$ Considering the large number of people who currently have or will have T2DM and the difficulties providers face in establishing glycemic control it becomes clear that there is a need for new agents with novel mechanisms of action to increase the number of options available to both patients and healthcare providers.

Dipeptidyl peptidase-4 (DPP-4) inhibitors represent a new therapeutic target for the treatment of T2DM. The first DPP-4 inhibitor to be approved by the US Food and Drug Administration (FDA) was sitagliptin (Januvia ${ }^{\mathrm{TM}}$ ) in October 2006. Sitagliptin is approved for use as monotherapy or as add-on therapy to ongoing metformin, thiazolidinedione, sulfonylurea ( \pm metformin.) A fixed-dose combination tablet 
containing both sitagliptin and metformin (Janumet ${ }^{\mathrm{TM}}$ ) was approved by the FDA in April 2007 and is marketed by Merck Pharmaceuticals. This fixed-dose combination tablet is available to provide patients requiring both sitagliptin and metformin to meet their A1C goals. The other DPP-4 inhibitor that is currently in use is vildagliptin which is available in the EU but not in the USA.

\section{Mechanism of action}

\section{Sitagliptin}

Insulin is secreted in response to elevation of plasma glucose. But it has been found that oral glucose intake augments insulin secretion three- to four-fold more as compared to an intravenous infusion of glucose that results in an identical elevation of plasma glucose. ${ }^{7}$ This augmentation of insulin secretion following the intake of oral glucose is known as the incretin effect. The effect is due to the release of incretins which are gut-derived hormones that are capable of potentiating the release of glucose dependent insulin secretion from the pancreas. ${ }^{7}$ Incretins are released into circulation after ingestion of food. Once in circulation they stimulate insulin release from the pancreas in a glucosedependent manner. ${ }^{8}$

GLP-1 which is released from the endocrine L cells of the small intestine and GIP which is released from the $\mathrm{K}$ cells ${ }^{7,9}$ are two of the incretin hormones that increase insulin secretion in the presence of elevated glucose concentrations. The incretin effect of GLP-1 and GIP is additive and together they are responsible for the majority of the incretin action which accounts for approximately $60 \%$ of the postprandial insulin response. ${ }^{7}$ In addition to directly increasing insulin secretion in a glucose-dependent manner, incretins exert other effects that help contribute to glycemic control. These other effects include; inhibiting appetite, ${ }^{10}$ lowering glucagon secretion, ${ }^{11}$ decreasing gastrointestinal motility, and delaying gastric emptying. ${ }^{12,13}$

It has been found that lower concentrations of active GLP-1 is associated with an inadequate insulin response. ${ }^{14}$ And patients with T2DM have almost no, or a greatly reduced incretin effect. ${ }^{7}$

The GLP-1 and GIP that are released from the L and $\mathrm{K}$ cells respectively are rapidly degraded and inactivated through metabolism mediated by the DPP-4 enzyme. ${ }^{11}$ It is estimated that upwards of $75 \%$ of the GLP-1 is inactivated before leaving the intestines and $40 \%-50 \%$ of the remaining GLP-1 is then degraded in the liver. This leaves only about $10 \%-15 \%$ of GLP-1 to enter systemic circulation. ${ }^{15}$
DPP-4 is a serine protease located on the surface of cells in the kidneys, intestines, bone marrow, liver, pancreas, placenta, thymus, spleen, epithelial cells, vascular endothelium, and lymphoid and myeloid cells. ${ }^{14}$ DDP-4 inhibitors such as sitagliptin block the enzymatic inactivation of the incretins which results in higher levels of active incretins in circulation. The release of incretins is dependent upon the presence of nutrients in the gut. Since the insulin-releasing effects of the incretins are glucosedependent, insulin levels are only increased in response to the body's need for insulin which decreases the patient's risk of hypoglycemia while still improving glycemic control. ${ }^{11}$

\section{Metformin}

While the mechanisms of action through which metformin exerts its various effects remains somewhat unclear, it is clear that metformin contributes to glycemic control in a variety of ways. In a review of the available research in 1999, Wiernsperger and Bailey reported that metformin assists in glycemic control in many ways including reducing hepatic glucose output, increasing peripheral glucose utilization, decreasing fatty acid oxidation, reducing appetite and weight gain, and sensitizing peripheral tissue to insulin action, increasing the functional activity of glucose transporters, and increasing insulin-mediated insulin receptor tyrosine kinase activity, which then augments a range of insulin signals. ${ }^{16}$

The precise mechanisms of action by which metformin lowers the basal and postprandial blood glucose in T2DM are not completely understood. But, it is thought that at least some of the therapeutic effects of metformin are mediated through GLP-1. ${ }^{17}$ Metformin significantly increases GLP-1 levels after an oral glucose load in obese nondiabetic patients. ${ }^{18}$ And it has been suggested that metformin does not directly inhibit DPP-4 but rather it enhances GLP-1 secretion. ${ }^{17}$ Since metformin appears to increase levels of GLP-1 in a different way than the DPP-4 inhibitors the combined effect of combination therapy with metformin and sitagliptin is thought to be complimentary.

\section{Efficacy}

When given as monotherapy ${ }^{19-23}$ and in combination with metformin, ${ }^{24-28}$ sitagliptin has been shown to be generally well tolerated and to improve A1C and other indices of glycemic control relative to placebo in patients with T2DM. $200 \mathrm{mg}$ once daily doses of sitagliptin did not show an efficacy advantage over sitagliptin $100 \mathrm{mg}$ once daily. ${ }^{20,21}$ Sitagliptin monotherapy administered in $50 \mathrm{mg}$ twice daily doses was found to be more effective than lower twice 
daily doses. ${ }^{19}$ The glycemic response between sitagliptin $100 \mathrm{mg}$ once daily did not differ from that of sitagliptin $50 \mathrm{mg}$ twice daily. ${ }^{23}$

The fixed-dose combination tablet of sitagliptin/ metformin is designed to be dosed twice daily and is available in two tablet strengths; sitagliptin $50 \mathrm{mg} / \mathrm{metformin} 500 \mathrm{mg}$ and sitagliptin $50 \mathrm{mg} / \mathrm{metformin} 1000 \mathrm{mg}$.

A study conducted by Goldstein and colleagues ${ }^{28}$ demonstrated the additive effect on glycemic control of combination therapy with sitagliptin and metformin. This was a randomized, placebo-controlled, parallel-group, double-blind study of 1,091 patients with T2DM who were inadequately controlled on diet and exercise alone (A1C of $7.5 \%-11 \%$ ) that was conducted over a 24 -week period. Subjects were randomized to one of six arms to receive placebo, metformin monotherapy, sitagliptin monotherapy, or sitagliptin/metformin combination therapy. ${ }^{28}$ Relative to placebo, all active treatments showed significant reductions in $\mathrm{A} 1 \mathrm{C}(\mathrm{P}<0.001)$ at week 24 as compared to baseline (Table 1). It was found that sitagliptin monotherapy $(n=175)$ lowered A1C by approximately $0.66 \%$ as compared to baseline and that metformin monotherapy $(n=177)$ lowered A1C by approximately $1.13 \%$. It was also found that the sitagliptin $50 \mathrm{mg} / \mathrm{metformin} 1,000 \mathrm{mg}$ combination $(\mathrm{n}=178)$ lowered A1C by approximately $1.9 \%$ as compared to baseline. The magnitude of the placebo-adjusted reduction in $\mathrm{A} 1 \mathrm{C}$ in the combination therapy groups as compared to the monotherapy groups demonstrates that there is an additive response when sitagliptin and metformin are given together. ${ }^{28}$

Several other trials have been conducted that added sitagliptin to patients with T2DM who were currently under poor control with metformin or other therapy for glycemic control $^{21,22,24-27,29}$ (Table 2). FDA approval of fixed-dose metformin/sitagliptin (Janumet ${ }^{\mathrm{TM}}$ ) was based on the study by Charbonnel and colleagues that concluded that the addition of sitagliptin $100 \mathrm{mg}$ dosed once daily to ongoing metformin therapy was efficacious and well tolerated in patients with T2DM who were inadequately controlled on metformin therapy alone. ${ }^{25}$

\section{Kinetics}

The oral bioavailability of sitagliptin is $87 \%$. Administering sitagliptin with food does not alter the $\mathrm{T}_{\max }$ or the half life. The volume of distribution is $198 \mathrm{~L}$ and it is approximately $38 \%$ bound to plasma proteins. ${ }^{30}$ Sitagliptin is a minor substrate for CYP 3A4 and 2C837 but it is neither an inhibitor nor an inducer of the $\mathrm{P} 450$ system $^{30}$ and moderate hepatic impairment does not appear to significantly alter the pharmacokinetic profile of sitagliptin. ${ }^{31}$ The primary elimination route of sitagliptin is via active tubular secretion in the kidneys $(\sim 79 \%)$ and the terminal half-life is $8-12$ hours. Dosage adjustments are recommended in moderate to severe renal impairment. ${ }^{32}$ There appears to be no clinically important pharmacokinetic interactions requiring dosage adjustment with agents co-administered with sitagliptin. ${ }^{33}$

\section{Safety \\ Sitagliptin}

In 2007, Amori and colleagues conducted a systematic review on the efficacy and safety of incretin therapy. The incretin therapy they studied included two incretin memetics or GLP-1 analogues; exenatode, liraglutide and two DPP-4 inhibitors; sitagliptin and vildagliptin. The findings for the two DPP-4 inhibitors were reported together in the review. ${ }^{34}$

Both of the DPP-4 inhibitors were found to lower A1C similarly compared with placebo $(-0.74 \%$ for sitagliptin and $-0.73 \%$ for vildagliptin). The DPP-4 inhibitors were slightly less effective compared with other hypoglycemic agents (weighted mean difference, $0.21 \%$; 95\% confidence interval [CI]: $0.02 \%-0.39 \%) .{ }^{34}$

Table I Glycosylated hemoglobin (AIC) endpoints for the treatment arms studied by Goldstein and colleagues ${ }^{28}$

\begin{tabular}{lllll}
\hline Treatment arm & $n$ & AIC at baseline & A IC at week 24 & $\begin{array}{l}\text { Change in AIC (\%) from } \\
\text { baseline to week 24 }\end{array}$ \\
\hline $\begin{array}{l}\text { Metformin/sitagliptin } \\
\text { I,000 mg/50 mg bid }\end{array}$ & 178 & $8.76 \% \pm 0.95 \%$ & $6.87 \% \pm 1.09 \%$ & $-1.90 \%(-2.06 \%$ to $-1.74 \%)$ \\
$\begin{array}{l}\text { Metformin/sitagliptin } \\
500 \mathrm{mg} / 50 \mathrm{mg} \text { bid }\end{array}$ & 183 & $8.79 \% \pm 1 \%$ & $7.37 \% \pm 1.20 \%$ & $-1.40 \%(-1.56 \%$ to $-1.24 \%)$ \\
Metformin I,000 mg bid & 177 & $8.68 \% \pm 0.91 \%$ & $7.58 \% \pm 1.27 \%$ & $-1.13 \%(-1.29 \%$ to $-0.97 \%)$ \\
Metformin $500 \mathrm{mg}$ bid & 178 & $8.90 \% \pm 1 \%$ & $8.04 \% \pm 1.36 \%$ & $-0.82 \%(-0.98 \%$ to $-0.66 \%)$ \\
Sitagliptin $100 \mathrm{mg}$ qd & 175 & $8.87 \% \pm 0.99 \%$ & $8.18 \% \pm 1.45 \%$ & $-0.66 \%(-0.83$ to $-0.50 \%)$ \\
Placebo & 165 & $8.68 \% \pm 1 \%$ & $8.88 \% \pm 1.47 \%$ & $0.17 \%( \pm 0.00-0.33)$ \\
\hline
\end{tabular}


Table 2 Key features and conclusions of trials that added sitagliptin to patients with type 2 diabetes mellitus (T2DM) who were currently under poor control with metformin or other therapy for glycemic control

\begin{tabular}{|c|c|c|c|}
\hline Study authors & Treatment arms & $\mathbf{N}$ & Conclusions \\
\hline Hermansen et $\mathrm{al}^{27}$ & $\begin{array}{l}\text { Placebo + glimepiride Placebo + } \\
\text { glimepiride + metformin } \\
\text { Sitagliptin + glimepiride } \\
\text { Sitagliptin + glimepiride + } \\
\text { metformin }\end{array}$ & $\begin{array}{l}\text { Completed } \mathrm{N}=87 \text { Completed } \\
\mathrm{N}=92 \text { Completed } \mathrm{N}=83 \\
\text { Completed } \mathrm{N}=102\end{array}$ & $\begin{array}{l}\text { The addition of sitagliptin } 100 \mathrm{mg} \text { qd significantly } \\
\text { improved glycemic control in patients who were } \\
\text { inadequately controlled with glimepiride or } \\
\text { glimepiride + metformin }\end{array}$ \\
\hline Nauck et $\mathrm{al}^{24}$ & $\begin{array}{l}\text { Sitagliptin + metformin } \\
\text { Glipizide + metformin }\end{array}$ & $\begin{array}{l}\text { Completed } N=386 \\
\text { Completed } N=412\end{array}$ & $\begin{array}{l}\text { The addition of sitagliptin compared } \\
\text { with glipizide provided similar AIC lowering } \\
\text { efficacy over } 52 \text { weeks in patients on } \\
\text { ongoing metformin therapy }\end{array}$ \\
\hline Charbonnel et $\mathrm{al}^{25}$ & $\begin{array}{l}\text { Sitagliptin + metformin } \\
\text { Placebo + metformin }\end{array}$ & $N=464 N=237$ & $\begin{array}{l}\text { Sitagliptin } 100 \mathrm{mg} \text { qd added to ongoing metformin } \\
\text { therapy was efficacious and well tolerated in } \\
\text { patients with T2DM who were inadequately } \\
\text { controlled on metformin alone }\end{array}$ \\
\hline Brazg et $\mathrm{a}^{26}$ & $\begin{array}{l}\text { Placebo/sitagliptin } 50 \mathrm{mg} \text { bid + } \\
\text { metformin Sitagliptin } 50 \mathrm{mg} \\
\text { bid/placebo + metformin }\end{array}$ & $N=13 N=15$ & $\begin{array}{l}\text { Addition of sitagliptin } 50 \mathrm{mg} \text { b.i.d. to ongoing } \\
\text { metformin therapy was well tolerated and } \\
\text { improved glycemic control and } \beta \text {-cell function }\end{array}$ \\
\hline Raz et $a^{30}$ & $\begin{array}{l}\text { Placebo Sitagliptin } 100 \text { mg qd } \\
\text { Sitagliptin } 200 \text { mg qd }\end{array}$ & $N=110 N=205 N=206$ & $\begin{array}{l}\text { Sitagliptin was well tolerated and significantly } \\
\text { improved glycemic control in patients with T2DM } \\
\text { who were inadequately controlled on exercise } \\
\text { and diet. Sitagliptin } 100 \mathrm{mg} \text { qd had a slight } \\
\text { numerical benefit over sitagliptin } 200 \mathrm{mg} \text { qd }\end{array}$ \\
\hline Scott et a ${ }^{29}$ & $\begin{array}{l}\text { Placebo + metformin Sitagliptin } \\
100 \mathrm{mg} \text { qd + metformin } \\
\text { Rosiglitazone } 8 \mathrm{mg} \text { qd }+ \\
\text { metformin }\end{array}$ & $N=92 N=94 N=87$ & $\begin{array}{l}\text { Addition of sitagliptin was effective } \\
\text { and well tolerated in T2DM patients who were } \\
\text { inadequately controlled on metformin therapy } \\
\text { alone. Treatment with sitagliptin and rosiglitazone } \\
\text { produced similar reductions in AIC }\end{array}$ \\
\hline Aschner et $\mathrm{al}^{21}$ & $\begin{array}{l}\text { Placebo Sitagliptin } 100 \text { mg qd. } \\
\text { Sitagliptin } 200 \text { mg qd }\end{array}$ & $N=253 N=238 N=250$ & $\begin{array}{l}\text { Once daily sitagliptin monotherapy was well } \\
\text { tolerated improved glycemic control in the } \\
\text { fasting and postprandial states and improved } \\
\text { measures of } \beta \text {-cell function. Sitagliptin } 200 \mathrm{mg} \text { qd } \\
\text { was slightly favored over sitagliptin } 100 \mathrm{mg} \text { qd }\end{array}$ \\
\hline
\end{tabular}

Abbreviations: bid, twice daily; qd, once daily.

DPP-4 inhibitors were found to be more likely to lower A1C below $7 \%$ compared to placebo ( $43 \%$ vs $17 \%$, respectively; risk ratio [RR], $2.5 \%$; $95 \%$ CI: $2.1-2.8)$ with no difference between the two DPP-4 inhibitors. ${ }^{34}$

The DPP-4 inhibitors reduced fasting plasma glucose more than placebo and sitagliptin was favored over vildagliptin in this category. ${ }^{34}$

Weight was increased slightly with DPP-4 inhibitors as compared to placebo (weighted mean difference, $0.5 \mathrm{~kg}$; $95 \%$ CI: $0.3-0.7 \mathrm{~kg}$ ) noninferiority trials revealed the weight profile favored sitagliptin over glipizides $(-2.5 \mathrm{~kg}$ vs $1.0 \mathrm{~kg}$, respectively). ${ }^{34}$

The review found that none of the trials revealed any consistent changes in lipid profile with either DPP-4 inhibitor as compared with placebo but there were some improvements in triglycerides and low- and high-density lipoprotein cholesterol. ${ }^{34}$
The incidence of mild to moderate hypoglycemia was found to be the same between the DPP-4 inhibitors and comparator groups (1.6\% vs $1.4 \%$, respectively; RR, $1.0 ; 95 \%$ CI: $0.5-1.9)$ while severe hypoglycemia was only reported in two patients taking DPP-4 inhibitors.

The review found the DPP-4 inhibitors exhibited low absolute rates of adverse effects. The risk of nasopharyngitis (6.4\% for DPP-4 inhibitor vs $6.1 \%$ for comparator; RR, 1.2 , 95\% CI: $1.0-1.4)$, urinary tract infection (3.2\% for DPP-4 inhibitor vs $2.4 \%$ for comparator; RR, 1.5 ; $95 \%$ CI: $1.0-2.2$ ), and headache $(5.1 \%$ for DPP-4 inhibitor vs 3.9\% for comparator; RR, 1.4; 95\% CI: 1.1-1.7) was increased with DPP-4 therapy vs comparators. ${ }^{34}$

In 2009 the Cochrane Collaboration published a review of the research conducted on the DPP-4 inhibitors, sitagliptin and vildagliptin. ${ }^{35}$ The research was designed to assess the effects of DPP-4 inhibitors for T2DM. The review 
included 11 trials of good quality that evaluated sitagliptin therapy with a total of 6,743 patients. Six trials in the review compared sitagliptin monotherapy with placebo. ${ }^{19-23,28}$ Two trials compared sitagliptin use with other single agent hypoglycemic treatment. ${ }^{19,28}$ And six of the trials compared sitagliptin combination therapies with other combination therapies of hypoglycemic agents. ${ }^{19,24,25,27,28,36}$ Most of the studies lasted 24 weeks. ${ }^{35}$

The Cochrane review concluded that sitagliptin was overall well tolerated. The review found that all-cause infections showed a statistically significant increase after sitagliptin treatment (RR 1.15, 95\% CI: 1.02-1.31; P = 0.003). ${ }^{35}$

Severe hypoglycemia was not reported in patients taking sitagliptin. Headache was reported more often with DPP-4 inhibitors. Sitagliptin therapy did not result in weight gain but weight loss was found to be more pronounced following placebo therapy. ${ }^{35}$

None of the trials that were reviewed published data on mortality, cost of care, diabetic complications, or healthrelated quality of life. ${ }^{35}$

There are no clinically significant drug interactions with sitagliptin. Sitagliptin $200 \mathrm{mg}$ given once daily for five days to 12 patients (nine men and three women) did not alter the pharmacokinetics of simvastatin given as one $20 \mathrm{mg}$ dose on day 5 of sitagliptin therapy. ${ }^{37}$ Likewise the pharmacokinetics of rosiglitazone were not altered by coadministration of a daily dose of $200 \mathrm{mg}$ of sitagliptin in 12 patients (eight men and four women). ${ }^{38}$ Coadministration of $100 \mathrm{mg}$ of sitagliptin daily with one dose of $600 \mathrm{mg}$ of cyclosporine caused the $t^{1} / 2$ of sitagliptin to fall from 11.6 hours to 10.6 hours $(\mathrm{P}=0.016)$, increased the $\mathrm{C}_{\max }$ of sitagliptin from $706 \mathrm{nmol} / \mathrm{L}$ to $1185 \mathrm{nmol} / \mathrm{L}$ and increased the renal clearance of sitagliptin from $92 \mathrm{ml} / \mathrm{min}$ to $121 \mathrm{ml} / \mathrm{min} .{ }^{39}$ $0.25 \mathrm{mg}$ of digoxin co-adminstered daily with $100-200 \mathrm{mg}$ of sitagliptin for at least 10 days resulted in an increase in the area under curve (AUC) of digoxin of $11 \%$ and $18 \%$, respectively, and a small increase in the fraction of digoxin excreted in the urine was observed. ${ }^{40}$

\section{Metformin}

The reported incidence of lactic acidosis in patients receiving metformin hydrochloride is very low (approximately 0.03 cases per 1,000 patient-years, with approximately 0.015 fatal cases per 1,000 patient-years). ${ }^{41}$ Reported cases have occurred primarily in diabetic patients with significant renal insufficiency. ${ }^{41}$ In patients with decreased renal function the plasma and blood half-life of metformin is prolonged and the renal clearance is decreased in proportion to the decrease in creatinine clearance. ${ }^{41}$ The risk of lactic acidosis increases with the degree of renal dysfunction and the patient's age. ${ }^{41}$

The most common side effects associated with metformin therapy largely involve the gastrointestinal system and include diarrhea, nausea/vomiting, flatulence, abdominal discomfort, indigestion, asthenia, and headache. ${ }^{41}$

\section{Combination sitagliptin/metformin}

No published studies have evaluated the long-term health outcomes of combination sitagliptin/metformin for treatment of TD2M.

Hypoglycemia was not found to be increased with the administration of combination therapy with sitagliptin and metformin. ${ }^{25}$

The package insert for Janumet ${ }^{\mathrm{TM}}$ offers additional safety information. ${ }^{41}$

- There are no adequate and well-controlled studies in pregnant women with Janumet ${ }^{\mathrm{TM}}$ or its components. Therefore its safety in pregnant women is unknown and it should only be used during pregnancy only if clearly needed. Caution is also advised in women who are breastfeeding. ${ }^{41}$

- Janumet ${ }^{\mathrm{TM}}$ is contraindicated in patients with renal disease or renal dysfunction due to the metformin component of the drug and the possible development of lactic acidosis. Janumet ${ }^{\mathrm{TM}}$ should not be initiated, and should be discontinued, in men with a serum creatinine $\geq 1.5 \mathrm{mg} / \mathrm{dL}$ and women with a serum creatinine $\geq 1.4 \mathrm{mg} / \mathrm{dL} .{ }^{41}$

- Janumet ${ }^{\mathrm{TM}}$ should not be used in patients with chronic metabolic acidosis, and should be used cautiously in those with a history of diabetic ketoacidosis. ${ }^{41}$

\section{Sitagliptin/metformin fixed-dose combination therapy adherence rates}

By taking fixed-dose combination products patients may be able to decrease the total number of pills taken during a day which potentially improves adherence to therapy.

No studies have been conducted to determine if adherence rates favor the fixed-dose combination of sitagliptin/metformin tablets or the co-administration of the components. However, studies have been conducted to determine if adherence rates differed between free-dose combination and fixed-dose combination forms of other drugs used to treat T2DM.

A retrospective database analysis was conducted by Melikian and colleagues ${ }^{42}$ that reviewed the rate of adherence of patients in a managed care organization who were 
taking glyburide or metformin monotherapy in free-dose combination or in fixed-dose combination. Patients were divided into two categories; newly treated patients who were not treated for diabetes prior to the index date (the first prescription fill during the identification period), and previously treated patients who were treated for diabetes prior to the index date.

The study concluded that for newly-treated patients there was no significant differences in adherence over the initial six months of pharmacologic therapy between patients receiving monotherapy or free-dose combination therapy compared with those receiving fixed-dose combination therapy. ${ }^{42}$ Significantly lower adherence rates were observed in patients receiving metformin or glyburide monotherapy in the pre-index period who had the alternative agent added, resulting in combination therapy, at the index date $(54 \%$; 95\% CI: $0.52-0.55)$ compared to those with a switch to fixed-dose glyburide/metformin combination therapy at the index date. ${ }^{42}$ There was a significant improvement in adherence rates in patients who had been receiving combination therapy in the pre-index period and were switched to fixeddose combination therapy at the index date (71\% vs $87 \%$; $\mathrm{p}<0.001){ }^{42}$

A study conducted by Blond and colleagues ${ }^{43}$ found similar results. The trial defined adherence as the total days' supply of medication during the study follow-up period divided by the length of the follow-up period. It was found that patients who were taking the fixed-dose form of glyburide/metformin had a drug supply on $84 \%$ of the days while those who were taking the co-administered components had a drug supply on $76 \%$ of the days. ${ }^{43}$

A retrospective database analysis was conducted by Vanderpoel and colleagues to asses changes in medication adherence rates associated with oral hypoglycemic agents in subjects switching from either monotherapy metformin or rosiglitazone or free-dose administration of rosiglitazone and metformin to fixed-dose administration of rosiglitazone/metformin. In this study a proxy measurement of medication adherence was calculated and higher by calculating a medication possession ratio (MPR). Higher scores were associated with increased adherence. The study concluded fixed-dose combination therapy yielded significant improvements in medication adherence rates compared with dual therapy regimens ${ }^{44}$ (Table 3 ).

\section{Sitagliptin/metformin fixed-dose combination efficacy compared to efficacy of other fixed-dose combination therapies for T2DM}

There has only been one study that attempted to compare the efficacy of sitagliptin/metformin combination therapy with any other drug given in combination with metformin. Nauck and colleagues compared sitagliptin/metformin with glipizide/metformin combination therapy. This study concluded that the addition of $100 \mathrm{mg}$ of sitagliptin to ongoing metformin therapy provided similar A1C-lowering effects as the addition of glipizide in 5 to $20 \mathrm{mg}$ daily doses to ongoing metformin therapy. ${ }^{24}$ The side effect profile favored the sitagliptin/metformin-treated patients over the glipizide/metformin-treated patients. More of the glipizide/ metformin-treated patients developed hypoglycemia than the sitagliptin/metformin-treated patients (32\% vs 5\%). Weight gain was more of an issue for the glipizide/metformin-treated patients than the sitagliptin/metformin-treated patients (+1.1 kg with glipizide and $-1.5 \mathrm{~kg}$ with sitagliptin).$^{24}$ Cost considerations likely would favor treatment with glipizide/ metformin over sitagliptin/metformin since generic forms

Table 3 Endpoints for the treatment arms studied by Vanderpoel and colleagues ${ }^{44}$

\begin{tabular}{llll}
\hline Therapy & $n$ & $\begin{array}{l}\text { Medication possession } \\
\text { ratios pre-index }\end{array}$ & $\begin{array}{l}\text { Medication possession } \\
\text { ratios post-index }\end{array}$ \\
\hline $\begin{array}{l}\text { Remained on monotherapy } \\
\text { throughout study }\end{array}$ & $\mathrm{N}=14291$ & 0.90 & 0.89 \\
$\begin{array}{l}\text { Switched to free-dose combination } \\
\text { therapy after index date }\end{array}$ & $\mathrm{N}=93 \mathrm{I}$ & 0.80 & 0.67 \\
$\begin{array}{l}\text { Switched to a fixed-dose combination } \\
\text { after index date }\end{array}$ & $\mathrm{N}=349$ & 0.87 & 0.83 \\
$\begin{array}{l}\text { Remained on free-dose combination } \\
\text { therapy after index date }\end{array}$ & $\mathrm{N}=1,230$ & 0.84 & 0.83 \\
$\begin{array}{l}\text { Switched the fixed-dose combination } \\
\text { therapy after index date }\end{array}$ & $\mathrm{N}=127$ & 0.79 & 0.82 \\
\hline
\end{tabular}


of metformin and glipizide are available and since generic forms of sitagliptin alone or in fixed-dose combination with metformin are not.

\section{Place in therapy of fixed-dose combination therapy sitagliptin/ metformin}

There are now five therapeutic classes of drugs available to be used for glycemic control in patients with T2DM; biguanides (eg, metformin), insulin secretagogues (eg, sulfonylureas), thiazolidinediones, alpha glycosidase inhibitors, and DPP-4 inhibitors. Five unique drugs are currently available in fixeddose combination with metformin; glyburide/metformin, glipizide/metformin, rosiglitazone/metformin, pioglitazone/ metformin, and now sitagliptin/metformin. With so many choices available, it is important to have an understanding of why prescribers might select one drug over the other. Prescribing decisions depend on other factors such as side-effect profiles, adherence and cost in cases where the comparative efficacies of therapies are similar.

The combined formulation of sitagliptin and metformin finds a niche with patients currently taking both sitagliptin and metformin as separate pills although the dosing flexibility of the metformin component diminishes when it is given in fixed-dose combination with sitagliptin. Patients who are insufficiently controlled on either sitagliptin or metformin alone are also candidates for the fixed-dose combination therapy.

\section{Conclusion}

Patients who are using free-dose combination therapy sitagliptin/metformin may benefit from switching to the fixed-dose combination therapy.

Other patients who may benefit from fixed-dose combination therapy with sitagliptin/metformin include those patients with hyperglycemia who are uncontrolled on metformin or sitagliptin alone, those who tend toward hypoglycemia when taking sulfonylureas in combination with metformin, and patients with T2DM for whom weight gain is a component of their disease and who may be at increased risk for congestive heart failure.

Finally fixed-dose combination therapy with sitagliptin/ metformin may be a reasonable choice for patients who are at an increased risk of heart disease. Both pioglitazone $\left(\right.$ Actose $^{\circledR}$ ) and rosiglitazone (Avandia ${ }^{\circledR}$ ) have FDA "black box" warnings that indicate they may cause or worsen congestive heart failure and their side effects include fluid retention, weight gain, and in rare cases, worsening of heart failure and its symptoms. ${ }^{45}$ Fixed-dose combination therapy with sitagliptin/metformin provides an option for patients and practitioners who are looking to decrease their pill burden and maximize medication adherence.

\section{Disclosure}

The author reports no conflicts of interest in this work.

\section{References}

1. Centers for Disease Control and Prevention. National Diabetes Fact Sheet, 2007. Accessed February 18, 2009. Available from: http://www. cdc.gov/diabetes/pubs/pdf/ndfs_2007.pdf.

2. Reynolds JK, Neumiller JJ, Campbell RK. Janumet: a combination product suitable for use in patients with Type 2 diabetes. Expert Opin Investig Drugs. 2008;17:1559-1565.

3. The effect of intensive treatment of diabetes on the development and progression of long-term complications in insulin-dependent diabetes mellitus. The Diabetes Control and Complications Trial Research Group. N Engl J Med. 1993;329:977-986.

4. Intensive blood-glucose control with sulphonylureas or insulin compared with conventional treatment and risk of complications in patients with type 2 diabetes (UKPDS 33). UK Prospective Diabetes Study (UKPDS) Group. Lancet. 1998;352:837-853.

5. Cefalu WT. Evaluation of alternative strategies for optimizing glycemia: progress to date. Am J Med. 2002;113(Suppl 6A):23S-35S.

6. Krentz AJ, Patel MB, Bailey CJ. New drugs for type 2 diabetes mellitus: what is their place in therapy? Drugs. 2008;68:2131-2162.

7. Holst JJ, Gromada J. Role of incretin hormones in the regulation of insulin secretion in diabetic and nondiabetic humans. Am J Physiol Endocrinol Metab. 2004;287:E199-E206.

8. Holst JJ, Deacon CF. Inhibition of the activity of dipeptidyl-peptidase IV as a treatment for type 2 diabetes. Diabetes. 1998;47:1663-1670.

9. Gallwitz B. Sitagliptin with metformin: profile of a combination for the treatment of type 2 diabetes. Drugs Today (Barc). 2007;43:681-689.

10. Verdich C, Flint A, Gutzwiller JP, et al. A meta-analysis of the effect of glucagon-like peptide-1 (7-36) amide on ad libitum energy intake in humans. J Clin Endocrinol Metab. 2001;86:4382-4389.

11. Deacon CF, Ahren B, Holst JJ. Inhibitors of dipeptidyl peptidase IV: a novel approach for the prevention and treatment of Type 2 diabetes? Expert Opin Investig Drugs. 2004;13:1091-1102.

12. Wettergren A, Schjoldager B, Mortensen PE, Myhre J, Christiansen J, Holst JJ. Truncated GLP-1 (proglucagon 78-107-amide) inhibits gastric and pancreatic functions in man. Dig Dis Sci. 1993;38:665-673.

13. Nauck MA, Niedereichholz U, Ettler R, et al. Glucagon-like peptide 1 inhibition of gastric emptying outweighs its insulinotropic effects in healthy humans. Am J Physiol. 1997;273:E981-E988.

14. Miller S, St Onge EL. Sitagliptin: a dipeptidyl peptidase IV inhibitor for the treatment of type 2 diabetes. Ann Pharmacother. 2006;40: $1336-1343$.

15. Holst JJ, Deacon CF. Glucagon-like peptide-1 mediates the therapeutic actions of DPP-IV inhibitors. Diabetologia. 2005;48:612-615.

16. Wiernsperger NF, Bailey CJ. The antihyperglycaemic effect of metformin: therapeutic and cellular mechanisms. Drugs. 1999; 58(Suppl 1):31-39; discussion, 75-82.

17. Yasuda N, Inoue T, Nagakura T, et al. Enhanced secretion of glucagonlike peptide 1 by biguanide compounds. Biochem Biophys Res Commun. 2002;298:779-784.

18. Mannucci E, Ognibene A, Cremasco F, et al. Effect of metformin on glucagon-like peptide 1 (GLP-1) and leptin levels in obese nondiabetic subjects. Diabetes Care. 2001;24:489-494.

19. Scott R, Wu M, Sanchez M, Stein P. Efficacy and tolerability of the dipeptidyl peptidase-4 inhibitor sitagliptin as monotherapy over 12 weeks in patients with type 2 diabetes. Int J Clin Pract. 2007;61: 171-180. 
20. Nonaka K, Kakikawa T, Sato A, et al. Efficacy and safety of sitagliptin monotherapy in Japanese patients with type 2 diabetes. Diabetes Res Clin Pract. 2008;79:291-298.

21. Aschner P, Kipnes MS, Lunceford JK, Sanchez M, Mickel C, WilliamsHerman DE. Effect of the dipeptidyl peptidase-4 inhibitor sitagliptin as monotherapy on glycemic control in patients with type 2 diabetes. Diabetes Care. 2006;29:2632-2637.

22. Raz I, Hanefeld M, Xu L, Caria C, Williams-Herman D, Khatami H. Efficacy and safety of the dipeptidyl peptidase-4 inhibitor sitagliptin as monotherapy in patients with type 2 diabetes mellitus. Diabetologia. 2006;49:2564-2571.

23. Hanefeld M, Herman GA, Wu M, Mickel C, Sanchez M, Stein PP. Once-daily sitagliptin, a dipeptidyl peptidase-4 inhibitor, for the treatment of patients with type 2 diabetes. Curr Med Res Opin. 2007;23:1329-1339.

24. Nauck MA, Meininger G, Sheng D, Terranella L, Stein PP. Efficacy and safety of the dipeptidyl peptidase- 4 inhibitor, sitagliptin, compared with the sulfonylurea, glipizide, in patients with type 2 diabetes inadequately controlled on metformin alone: a randomized, doubleblind, non-inferiority trial. Diabetes Obes Metab. 2007;9:194-205.

25. Charbonnel B, Karasik A, Liu J, Wu M, Meininger G. Efficacy and safety of the dipeptidyl peptidase- 4 inhibitor sitagliptin added to ongoing metformin therapy in patients with type 2 diabetes inadequately controlled with metformin alone. Diabetes Care. 2006;29: 2638-2643.

26. Brazg R, Xu L, Dalla Man C, Cobelli C, Thomas K, Stein PP. Effect of adding sitagliptin, a dipeptidyl peptidase-4 inhibitor, to metformin on 24-h glycaemic control and beta-cell function in patients with type 2 diabetes. Diabetes Obes Metab. 2007;9:186-193.

27. Hermansen K, Kipnes M, Luo E, Fanurik D, Khatami H, Stein P. Efficacy and safety of the dipeptidyl peptidase-4 inhibitor, sitagliptin, in patients with type 2 diabetes mellitus inadequately controlled on glimepiride alone or on glimepiride and metformin. Diabetes Obes Metab. 2007;9:733-745.

28. Goldstein BJ, Feinglos MN, Lunceford JK, Johnson J, WilliamsHerman DE. Effect of initial combination therapy with sitagliptin, a dipeptidyl peptidase-4 inhibitor, and metformin on glycemic control in patients with type 2 diabetes. Diabetes Care. 2007;30:1979-1987.

29. Scott R, Loeys T, Davies MJ, Engel SS. Efficacy and safety of sitagliptin when added to ongoing metformin therapy in patients with type 2 diabetes. Diabetes Obes Metab. 2008;10:959-969.

30. Langley AK, Suffoletta TJ, Jennings HR. Dipeptidyl peptidase IV inhibitors and the incretin system in type 2 diabetes mellitus. Pharmacotherapy. 2007;27:1163-1180.

31. Stevens C, Bergman A, Liu Q, et al. Lack of clinically significant effect of moderate hepatic insufficiency on the pharmacokinetics of MK-0431 (sitagliptin), a dipeptidyl-peptidase-IV inhibitor [abstract no. PII-49]. Clin Pharmacol Ther. 2006;79:1.
32. Bergman AJ, Cote J, Yi B, et al. Effect of renal insufficiency on the pharmacokinetics of sitagliptin, a dipeptidyl peptidase-4 inhibitor. Diabetes Care. 2007;30:1862-1864.

33. Scheen AJ. Clinical pharmacokinetics of metformin. Clin Pharmacokinet. 1996;30:359-371

34. Amori RE, Lau J, Pittas AG. Efficacy and safety of incretin therapy in type 2 diabetes: systematic review and meta-analysis. JAMA. 2007;298:194-206.

35. Richter B, Bandeira-Echtler E, Bergerhoff K, Lerch CL. Dipeptidyl peptidase-4 (DPP-4) inhibitors for type 2 diabetes mellitus. Cochrane Database Syst Rev. 2008;2:CD006739.

36. Rosenstock J, Brazg R, Andryuk PJ, Lu K, Stein P. Efficacy and safety of the dipeptidyl peptidase-4 inhibitor sitagliptin added to ongoing pioglitazone therapy in patients with type 2 diabetes: a 24 -week, multicenter, randomized, double-blind, placebo-controlled, parallelgroup study. Clin Ther. 2006;28:1556-1568.

37. Bergman AJ, Cote J, Maes A, et al. Effect of sitagliptin on the pharmacokinetics of simvastatin. J Clin Pharmacol. 2009;49:483-488.

38. Mistry GC, Bergman AJ, Luo WL, et al. Multiple-dose administration of sitagliptin, a dipeptidyl peptidase-4 inhibitor, does not alter the single-dose pharmacokinetics of rosiglitazone in healthy subjects. J Clin Pharmacol. 2007;47:159-164.

39. Krishna R, Bergman A, Larson P, et al. Effect of a single cyclosporine dose on the single-dose pharmacokinetics of sitagliptin (MK-0431), a dipeptidyl peptidase-4 inhibitor, in healthy male subjects. J Clin Pharmacol. 2007;47:165-174.

40. Miller JL, Migoya E, J.E. T. The effect of MK-0431 on the pharmakokinetics of digoxin after concomitant administration for 10 days in healthy subjects. Clin Pharmacol Ther. 2006;79.

41. Janumet ${ }^{\mathrm{TM}}$ (sitagliptin/metformin $\mathrm{HCl}$ ) Tablets [package insert]. Whitehouse Station, NJ: Merck Pharmaceuticals, Inc; 2007.

42. Melikian C, White TJ, Vanderplas A, Dezii CM, Chang E. Adherence to oral antidiabetic therapy in a managed care organization: a comparison of monotherapy, combination therapy, and fixed-dose combination therapy. Clin Ther. 2002;24:460-467.

43. Blonde L, Wogen J, Kreilick C, Seymour AA. Greater reductions in $\mathrm{A} 1 \mathrm{C}$ in type 2 diabetic patients new to therapy with glyburide/metformin tablets as compared to glyburide co-administered with metformin. Diabetes Obes Metab. 2003;5:424-431.

44. Vanderpoel DR, Hussein MA, Watson-Heidari T, Perry A. Adherence to a fixed-dose combination of rosiglitazone maleate/metformin hydrochloride in subjects with type 2 diabetes mellitus: a retrospective database analysis. Clin Ther. 2004;26:2066-2075.

45. Sarafidis PA. Thiazolidinedione derivatives in diabetes and cardiovascular disease: an update. Fundam Clin Pharmacol. 2008;22: 247-264.

\section{Publish your work in this journal}

Diabetes, Metabolic Syndrome and Obesity: Targets and Therapy is an international, peer-reviewed open-access journal committed to the rapid publication of the latest laboratory and clinical findings in the fields of diabetes, metabolic syndrome and obesity research. Original research, review, case reports, hypothesis formation, expert opinion and commentaries are all considered for publication. The manuscript management system is completely online and includes a very quick and fair peer-review system, which is all easy to use. Visit http://www.dovepress.com/testimonials.php to read real quotes from published authors. 